\title{
¿NATURALIZAR LA IDEA DE JUSTICIA? UNA RESPUESTA CRÍTICA DESDE LA TEORÍA MORAL DE JÜRGEN HABERMAS ${ }^{1}$
}

\author{
CÉSAR ORTEGA ESQUEMBRE \\ Universidad de Valencia
}

\begin{abstract}
RESUMEN: El presente artículo pretende abordar críticamente las actuales tendencias naturalistas en ética, herederas tanto del evolucionismo como de las neurociencias, desde la teoría moral de Jürgen Habermas. Para ello se bosquejará una aproximación al uso específicamente moral de la razón práctica, tal y como lo propone Habermas; se equiparará dicho uso con el nivel posconvencional de desarrollo ontogenético de la conciencia moral, según la teoría del desarrollo moral de Kohlberg; y se argumentará que las explicaciones naturalistas no pueden dar cuenta de dicho nivel, que cabe entender como el ámbito específico de la justicia.
\end{abstract}

PALABRAS CLAVE: conciencia moral, justicia, éxito evolutivo, Habermas, Kohlberg.

\section{A naturalized concept of justice? A critical response based on Jürgen Habermas's moral theory}

ABSTRACT: The aim of this paper is to study critically, with the help of Habermas's moral theory, the current naturalistic approach to morality - which is based on both the evolutionary theory and neuroscience-. In doing so it will be explained the specifically moral use of practical reason, as Habermas propose; it will be compared this moral use with Kohlberg's postconventional stage of moral development; and it will be claimed that naturalistic approach cannot explain this stage, that can be understood as specific justice area.

KEY WORDS: moral consciousness, justice, evolutionary success, Habermas, Kohlberg.

\section{INTRODUCCIÓN}

Las actuales corrientes naturalistas en ética, basadas en las nuevas informaciones acerca del funcionamiento cerebral proporcionadas por la neurociencia y en la teoría de la evolución, tienen por objeto explicar empíricamente ciertos fenómenos relacionados con el mundo moral, hasta hace poco reservados a la ética filosófica. Determinadas evidencias observacionalmente delimitables, tal es la tesis que subyace a estas corrientes, pueden agotar la explicación de la moralidad sin necesidad de recurrir a conceptos normativos.

Esta naturalización de la ética encuentra sin embargo un escollo fundamental tan pronto como deja de limitar su análisis al estudio de la aparición

1 El presente trabajo se enmarca dentro del proyecto I+D «Juicio Moral, Justicia y Democracia en Perspectiva Neuorética» (referencia: FFI2013-47136-C2-1-P), financiado con fondos del MINECO. 
filogenética de la conciencia y agencia morales ${ }^{2}$ y transita hacia un estudio de dicha conciencia en los niveles más elevados de desarrollo ontogenético; es decir, cuando el objeto de análisis deja de ser el surgimiento evolutivo de la moralidad, y pasa a ser la especificidad de la moralidad ya constituida, que podríamos denominar el punto de vista moral $^{3}$. Naturalmente, la afirmación anterior parte tanto de la hipótesis, inaugurada por la psicología cognitivo-evolutiva de Piaget y continuada por Kohlberg, de que existe una evolución ontogenética de la conciencia moral, como de la hipótesis, que trataremos de escudriñar aquí, de que los últimos estadios de ese desarrollo no resultan fácilmente analizables bajo conceptos naturalistas -en concreto, bajo la noción de éxito adaptativo.

Desde luego que el estudio de la historia filogenética del ser humano, y en consecuencia del desarrollo evolutivo del cerebro, debe cumplir un papel importante en la dilucidación de la moralidad. Tal investigación, claro está, ha de contar con una ciencia que proceda mediante objetivación. Sin embargo, y ésta es la idea de la que se desea partir, no parece tan fácilmente discernible si ese tipo de estudio naturalista agota la especificidad de la moralidad humana, una vez ha sido constituida, o si más bien explica sólo parcialmente un fenómeno en realidad mucho más complejo.

El propósito de este trabajo es analizar si las categorías usadas por la explicación natural-evolucionista de la moralidad, ciertamente necesarias en el plano filogenético, resultan adecuadas para abordar los estadios más avanzados de desarrollo ontogenético de la conciencia moral. Para ello se expondrá una categorización de los diversos usos de la razón práctica, siguiendo la propuesta de Habermas (I); a continuación se dibujará la teoría del desarrollo moral de Kohlberg, exponiendo las características esenciales de cada uno de los tres niveles de desarrollo del juicio moral (II); se procederá tras ello a explorar la hipótesis de una correlación entre los diversos usos de la razón práctica expuestos por Habermas y los niveles de Kohlberg (III); en cuarto lugar se expondrán algunos rasgos de las tentativas naturalistas (IV); para finalizar respondiendo a la siguiente pregunta: ¿pueden estas tentativas explicar el uso moral de la razón, es decir, el momento en que la razón práctica adopta el rol de un "punto de vista moral», que de confirmarse nuestra hipótesis se identificaría con el nivel posconvencional en la teoría de Kohlberg? Si a su vez equiparamos este nivel con el plano de la justicia, para lo cual habría de entenderse el «punto de vista moral» como el momento que garantiza la imparcialidad del juicio, esta pregunta podría quedar mejor formulada en los siguientes términos, recientemente utilizados por Jesús Conill: ¿puede también naturalizarse la justicia? ${ }^{4}(\mathrm{~V})$.

2 Para un estudio de la conciencia moral en clave neuroética véase en este mismo monográfico Cortina, A., «La conciencia moral desde una perspectiva neuroética. De Darwin a Kant».

3 Este concepto no es particularmente bien acogido por algunos autores de la moderna tradición naturalista. Véase KITcheR, P., «Is a naturalized ethics possible?»,donde se lo define como «una mera ficción filosófica».

${ }_{4}$ La pregunta fue formulada por Jesús Conill en el contexto de un seminario de investigación. 


\section{Los USOS DE LA RAZÓN PRÁCtICA SEGÚN JÜRGEN HABERMAS}

En el capítulo quinto de sus Aclaraciones a la ética del discurso, Jürgen Habermas expone una interesante categorización de los diversos usos que, a su juicio, puede adoptar la razón práctica. Esta tipificación, con la que Habermas pretende reconstruir las distintas formas en que el ser humano ya constituido hace uso de dicha razón, resulta sumamente pertinente a la hora de apresar la especificidad de la moralidad. Si cada una de las tres fuentes fundamentales de la filosofía moral y política, a saber, el utilitarismo, la ética aristotélica y la teoría moral kantiana, consiguieron ofrecer una explicación adecuada de cada uno de estos aspectos por separado, que Habermas denomina "pragmático», «ético» y «moral», la teoría del discurso es capaz de entender estos aspectos como usos específicos de la razón práctica ${ }^{5}$. Veamos cómo quedan categorizados.

En tanto comportándose pragmáticamente, la razón procede a la búsqueda de la decisión más racional a fin de alcanzar un objetivo preestablecido; bajo este actuar estratégico, cada sujeto supone en el resto de sujetos un interés egoísta, de suerte que, a la luz de una voluntad que ha sido ya «fijada fácticamente por deseos y valores $»^{6}$, la razón práctica recomienda las técnicas más adecuadas para la consecución de dichos deseos.

Tan pronto como los propios deseos, fines y valores se vuelven problemáticos, la razón ya no puede agotarse en el horizonte de un procedimiento instrumental. En este momento el «¿qué debo hacer?» deja de remitir a una finalidad no problematizada, para convertirse en una indagación reflexiva sobre los objetivos que uno tiene a la luz de los que en realidad desearía tener. Bajo su uso ético, la razón práctica abandona las preferencias meramente casuales para abordar la autocomprensión existencial del sujeto socializado, esto es, su identidad - tanto personal como grupal. «La razón práctica, que en este sentido apunta no sólo a lo posible e idóneo para obtener el fin de que se trate en cada caso, sino a lo bueno, se mueve [...] en el campo de la ética» ${ }^{7}$. A través de una "comprensión apropiadora», que apunta tanto a la biografía como a las tradiciones en que ésta ha sido modulada, la razón práctica procede a un autocercioramiento de la identidad.

Pero aunque las proposiciones éticas no hablan de meras preferencias subjetivas, tampoco hacen alusión a cuestiones de tipo absoluto: «lo que tú "debes" o "tienes" que hacer posee aquí el sentido de que a la larga y en conjunto "es bueno" para ti actuar de ese modo» ${ }^{8}$. Únicamente si una tal identidad reflejase una forma de vida incondicionalmente válida, continúa Habermas, «iría realmente en interés de todos por igual lo que desde mi perspectiva es bueno para

5 También Ricoeur ha diferenciado en un sentido similar al que expongo a continuación el uso ético — vinculado con lo bueno—y el moral — que apela a lo obligatorio. Véase RICOEUR, P., «Ética y moral».

6 Habermas, J., Aclaraciones a la ética del discurso, cap. V, 112.

7 Ibidem.

8 Ibidem, 113. 
todos por igual» ${ }^{9}$. Cuando la razón se encamina al análisis de la legitimidad de normas de acción ante cuya validez han de poder asentir todos los afectados, el uso ético de la razón deviene uso moral: sólo aquí los conflictos de acción pueden regularse desde puntos de vista genuinamente morales, es decir, desde la imparcialidad que representa el concepto de justicia.

Sólo el sentido imperativo de estos mandatos se puede entender como un deber que no depende de fines y preferencias subjetivos, ni tampoco del fin, para mí absoluto, de una vida buena, lograda o no malograda. Aquí, lo que se «debe» o «hay que» hacer tiene más bien el sentido de que es justo y por tanto es un deber actuar así10.

Mientras que en los discursos ético-existenciales los implicados no abandonan la biografía «en que se encuentran fácticamente», los discursos morales «exigen la ruptura con todas las obviedades de la eticidad concreta asimilada por acostumbramiento ${ }^{11}$.

Evidentemente, la biografía de un sujeto socializado no se agota en ninguno de estos tres usos de la razón práctica. Uno no puede, por así decirlo, juzgarlo todo bajo el punto de vista de la moralidad, como tampoco puede limitarse siempre al examen de las técnicas más adecuadas para la obtención de fines presupuestos. El discurso práctico, como prosecución de la acción comunicativa por otros medios, eleva al nivel de la reflexividad y enjuiciamiento crítico-moral pretensiones de validez y certezas presupuestas con las que en realidad los sujetos operan ya todo el tiempo en el mundo de la vida. Este recorrido bidireccional entre la acción y el discurso es analizado por Habermas en Verdad y justificación. «En la red de prácticas habituales las pretensiones de validez implícitamente sostenidas forman, por así decirlo, las vías por las que discurren aquellas certezas que dirigen la acción ${ }^{12}$. Tan pronto como estas certezas orientadoras de la praxis se vuelven problemáticas adquieren la forma de un enunciado hipotético cuya validez hay que defender, o criticar, en el discurso racional ${ }^{13}$ : «la argumentación tiene la forma de una pugna en torno a los mejores argumentos en favor o en contra de la pretensión de validez controvertida y sirve a la búsqueda cooperativa de la verdad» ${ }^{14}$. Si tales certezas problematizadas se justifican a su vez discursivamente, entonces pueden volver al contexto de acción como «verdades aceptadas». Si no consiguen pasar la prueba crítico-argumentativa, entonces han de ser desechadas como normas

$9 \quad$ Ibidem, 116.

$10 \quad$ Ibidem, 117.

11 Ibidem, 121.

12 Habermas, J., Verdad y justificación, cap. V, 244.

13 El carácter excesivamnte racionalista del procedimiento apeliano-habermasiano ha ocasionado en España una renovada ética del discurso que incorpora el papel de las emociones y apela a una razón experiencial. Véase CoRTinA, A., Ética de la razón cordial; Justicia cordial; Conill, J., Ética hermenéutica; «El carácter hermenéutico y deliberativo de las éticas aplicadas»; GARcía MARZÁ, D., «Neuropolítica y democracia».

14 Habermas, J., Verdad y justificación, 245. 
falsamente universalizadas — podríamos decir, en cierto modo, que el examen crítico-argumentativo adopta aquí la conocida forma de una crítica de las ideologías ${ }^{15}$. Naturalmente que Habermas debe explicar aún lo más importante, a saber, «la enigmática fuerza del acuerdo logrado por medios discursivos que autoriza a los participantes en la argumentación, en su papel de actores, a aceptar sin reservas como verdades las afirmaciones justificadas» ${ }^{16}$.

Es justamente esa «enigmática fuerza» la que Habermas, junto con Apel, trató de explicar mediante su teoría consensual de la corrección normativa. Por decirlo brevemente, Habermas cree posible distinguir la corrección normativa de la mera aceptabilidad racional en la medida en que se realice una «idealización de las condiciones de justificación». A su juicio, la propia praxis argumentativa obliga performativamente a los participantes a hacer presuposiciones pragmáticas de contenido contrafáctico, tales como «la inclusión, la participación igualitaria, la inmunización frente a coacciones externas o internas, o la orientación al entendimiento de los participantes» ${ }^{17}$. El análisis de esta fundamentación, localizado en Conciencia moral y acción comunicativa y Aclaraciones a la ética del discurso ${ }^{18}$, excede sin embargo los objetivos de este trabajo.

Regresando al punto de nuestra argumentación, podemos decir que bajo esta categorización la ética discursiva pretende ofrecer una reconstrucción racional del uso moral de la razón, o punto de vista moral, «desde los presupuestos comunicativos universales de la argumentación» ${ }^{19}$; es decir, un procedimiento para explicar el kantiano punto de vista moral mediante una lectura intersubjetiva del imperativo categórico:

El discurso moral-práctico significa la ampliación ideal de nuestra comunidad de comunicación desde cada perspectiva interior. En este foro solo pueden recibir aquiescencia fundamentada aquellas propuestas de normas que expresen un interés común de todos los afectados ${ }^{20}$.

La explicación del punto de vista moral se revela pues como la explicación de las condiciones «bajo las que los implicados mismos podrían encontrar en cada caso una respuesta racional ${ }^{21}$. La operación exigida por el punto de vista moral, a saber, la universalización de las máximas e intereses problematiza-

15 La disputa acontecida a finales de los años sesenta entre la tradición hermenéutica y la crítica de las ideologías, que arranca con una crítica de Habermas al Gadamer de Verdad y Método en La lógica de las ciencias sociales, fue recogida en APEL, K. O. et al. (ed.), Hermeneutik und Ideologiekritik. Posteriormente Paul Ricoeur participó en este debate con un texto titulado «Hermenéutica y crítica de las ideologías».

16 Habermas, J., Verdad y justificación, 245.

17 Ibidem, 249.

18 Véase especialmente Habermas, J., Aclaraciones a la ética del discurso, cap. VI; Conciencia moral y acción comunicativa, cap. III.

19 Habermas, J., Aclaraciones a la ética del discurso, cap. VI, 127.

20 Ibidem, 122.

21 Ibidem, 132. 
dos, obliga a cada participante a «trascender el contexto social e histórico de la forma de vida específica de cada uno de ellos y de su particular comunidad", de suerte que se adopte «la perspectiva de todos los posiblemente afectados». Tal y como habíamos señalado más arriba, es esta operación la que, rebasando el «horizonte del mundo de la vida específico de cada cultura dentro del cual se mueven los procesos éticos de autocomprensión ${ }^{22}$, ofrece un criterio para discernir cuáles, de entre los plurales valores e intereses de los diversos sujetos y grupos, resultan en rigor intereses universalizables. O dicho en una palabra: esta operación ofrece un criterio normativo para enjuiciar imparcialmente las cuestiones de justicia.

Si recordamos lo dicho en la introducción, para el objetivo de comprobar si las explicaciones naturalistas conseguían dar cuenta del estadio superior de desarrollo ontogenético de la conciencia moral nos habíamos propuesto analizar si dicho estadio podía equipararse al habermasiano uso moral de la razón práctica -o punto de vista moral—, que se ha revelado en este punto como equivalente al principio de justicia. Siendo ésta nuestra estrategia argumentativa, el siguiente paso habrá de ser un análisis de los diversos estadios evolutivos expuestos en la teoría de Kohlberg.

\section{La ontogénesis de la conciencia moral según Lawrence Kohlberg}

Si nos atenemos al objetivo fundamental del artículo, es evidente que una exposición pormenorizada de la teoría de Kohlberg — tanto psicológica como moral-, que habría de remontarse hasta la psicología constructivista de Piaget, no resulta pertinente. Así pues, vamos a limitarnos a exponer los diversos estadios de desarrollo ontogenético del juicio moral, tal y como los ha definido tradicionalmente Kohlberg.

La teoría cognitivista de Kohlberg, frente a otras vías de investigación psicológica de tipo conductista, psicoanalítico o sociológico, entiende la moralidad al modo de una construcción individual de principios autónomos, de suerte que su desarrollo aparece como el producto de una sistemática interacción entre las estructuras del sujeto y las estructuras del medio social a que dicho sujeto pertenece. Bajo estas premisas, Kohlberg se esfuerza por demostrar, partiendo de Piaget, que existe una estructura o forma de pensamiento moral racional universal, lo que significa que dicha forma de pensamiento podría ser articulada por toda persona - aunque no lo sea de hecho-independientemente de su cultura. En este sentido presenta su teoría, empíricamente avalada mediante el método de entrevistas de respuesta libre a niños de diferentes condiciones, como una suerte de esquema cognitivo-evolutivo de la moralización del niño. La ontogénesis hacia esta forma de pensamiento moral racional, tal es la tesis cognitivo-evolutiva, acontece de forma universal, de manera que en todas

22 Ibidem, 132, 133. 
las culturas el proceso de moralización pasa invariablemente por los mismos estadios - aunque evidentemente la organización socio-cultural potenciará o reprimirá, según el caso, unos u otros de estos estadios.

En la Introducción a su Psicología del desarrollo moral23, Kohlberg ubica el germen de su investigación sobre estadios morales en su tesis doctoral de 1958, donde se asumen los supuestos y metodologías de la teoría cognitivoevolutiva de la moralidad defendida años antes por Piaget, añadiéndose tres estadios más a la propuesta original. Ya en el capítulo primero de la obra, titulado «Estadio y secuencia: vía cognitivo-evolutiva hacia la socialización», Kohlberg localiza seis estadios diferenciados de juicio moral, entendiendo por estadio una secuencia invariante, irreversible y estructurada cuya integración se da jerárquicamente. Estos estadios estarían a su vez agrupados en tres niveles, que reciben el ya canónico nombre de «preconvencional», «convencional» y «posconvencional». Veamos los rasgos y subdivisiones de cada uno de ellos ${ }^{24}$.

Los juicios morales que el niño presenta en el nivel preconvencional se organizan en dos estadios. En el primero, que Kohlberg denomina «estadio de la orientación al castigo y la obediencia», el niño orienta su acción de acuerdo a una «tendencia a evitar problemas». En el estadio segundo el niño se encuentra en un «ingenuo hedonismo instrumental», en el que la acción correcta es aquélla que le reporta alguna forma de placer. Tal y como se expresa Kohlberg en «Del es al debe», en general en este primer nivel «la acción justa es la que satisface instrumentalmente las necesidades del yo».

En el nivel convencional el valor moral reside en «interpretar roles buenos o correctos», así como en "mantener el orden y las expectativas de los demás». Mientras que en el estadio tercero el niño se orienta tratando de agradar a los miembros del grupo, de suerte que acontece aquí por vez primera la "conformidad a imágenes estereotipadas de la mayoría»; en el cuarto estadio se da ya una nítida orientación hacia el «mantenimiento de la autoridad y del orden social dado». En términos general, en el nivel convencional «el comportamiento justo consiste en cumplir con el deber propio, mostrar respeto por la autoridad y mantener el orden social dado porque es valioso en sí mismo».

Los juicios morales pronunciados por el adolescente en el nivel posconvencional se basan en la «conformidad del ego con estándares, derechos o deberes compartidos o compartibles». En el estadio cinco, definido como «legalismo contractual», el joven entiende el deber en términos de contrato, y se orienta «evitando la violación de los derechos de otros y según la voluntad y bienestar de la mayoría». El último estadio es el estrictamente posconvencional. La orientación del joven hacia la justicia no está marcada ya por las reglas que ordena la sociedad, sino por principios individuales de conciencia «que requieren la llamada a una consistencia y universalidad lógica». Kohlberg afirma que

23 Kohlberg, L., Psicología del desarrollo moral.

24 En lo que sigue me remito a la tabla 1.2. de dicho capítulo. Véase KohlBerg, L., Psicología del desarrollo moral, 80. Hago también algunas referencias a KoHLBERG, L., «From Is to Ought». 
estos son "principios universales de justicia, de reciprocidad e igualdad de los derechos humanos y de respeto por la dignidad de los seres humanos como individuos».

Una vez expuestos brevemente los diferentes estadios evolutivos de Kohlberg podemos proceder al análisis de la hipótesis planteada en la introducción.

\section{Estadios EVOLUTIVOS Y USOS DE LA RAZÓN PRÁCTICA}

La relación existente entre la teoría normativa de Habermas y la teoría psicológica y moral- de Kohlberg resulta peculiarmente controvertida. Ya en los tempranos textos de La reconstrucción del materialismo histórico Habermas se sirve de los estudios de la psicología evolutiva para apuntalar su teoría de la evolución social, mostrando la existencia de un nexo clave entre las pautas de socialización y legitimación social de las distintas épocas y las formas de conciencia o «formas identitarias de la juventud $»^{25}$.

En un sentido diferente, la temprana autocomprensión positiva de Kohlberg con respecto a su propia teoría psicológica ${ }^{26}$ suscitó una interesante crítica de Habermas, aparecida en el capítulo segundo de su Conciencia moral y acción comunicativa ${ }^{27}$. El propio Kohlberg tomó en consideración esta crítica, y alejándose de aquella visión según la cual la teoría psicológica era suficiente para explicar la moralidad, terminó por reconocer que «una teoría psicológica adecuada de los estadios y de su avance presupone una teoría normativa de la justicia» ${ }^{28}$. Kohlberg acepta de Habermas que el éxito de una teoría empírica como la teoría de los estadios evolutivos, entendida como una reconstrucción racional de la ontogénesis del razonamiento de la justicia, puede a lo sumo funcionar como un "control para la validez normativa de una reconstrucción hipotética de las intuiciones morales ${ }^{29}$, pero nunca como una confirmación o falsación directa de la teoría normativa en que descansa. Así pues, «la verdad empírica de la secuencia ontogenética no garantiza una validez para las concepciones normativas de la justicia utilizadas en la reconstrucción racional» ${ }^{30}$, por mucho que la falsación de las hipótesis empíricas de la teoría psicológica pudiera suscitar considerables dudas a propósito de la teoría normativa.

Pero al margen de esta conexión entre Habermas y Kohlberg, a nosotros nos interesa analizar si es o no posible correlacionar los distintos niveles evolutivos

25 Habermas, J., La reconstrucción del materialismo histórico, cap. III. Para la teoría de la evolución social habermasiana véase Habermas, J., Problemas de legitimación en el capitalismo tardío. Para un estudio de la correlación entre sistemas sociales y sistema de personalidad, véase Cortina, A., Ética mínima, 117 y ss.

26 Kohlberg, L., Psicología del desarrollo moral, 231 y ss.

27 Habermas, J., Conciencia moral y acción comunicativa, cap. II, 31-51.

28 Kohlberg, L., Psicología del desarrollo moral, 231.

29 Ibidem, 230.

30 Ibidem. 
de la teoría de Kohlberg con los tres usos que Habermas atribuye a la razón práctica.

Vamos a proceder a un análisis paso por paso, comenzando por el intento de equiparar el uso pragmático de la razón práctica con el nivel preconvencional de desarrollo evolutivo. Bajo la lectura que hace Habermas del primer nivel, el universo simbólico del niño se compone únicamente de «expectativas de comportamiento", "acciones concretas» $\mathrm{y}$ "consecuencias de tales acciones» -sanciones o premios-; por lo demás, las necesidades del sujeto se generalizan sólo «en la dimensión del placer/displacer»" ${ }^{31}$. En el uso pragmático de la razón práctica, por su parte, el sujeto, suponiendo en todo otro sujeto un autointerés egoísta, se deja guiar por un actuar estratégico que recomienda las técnicas más adecuadas para la consecución de fines o deseos ya fácticamente prefijados. Parece ser que si bien el estadio primero de este nivel, donde el niño se orienta fundamentalmente mediante el intento de evitarse problemas, no se corresponde exactamente con el uso pragmático de la razón, este uso sí encuentra un reflejo bastante fiel en el estadio segundo, donde bajo un «ingenuo hedonismo instrumental» el niño entiende por correctas sólo aquellas acciones que satisfacen sus propias necesidades. El sujeto del estadio segundo, por así decirlo, guía su acción de acuerdo a unos criterios muy similares a los que rigen en el uso pragmático de la razón, a saber, el éxito en la procuración de satisfacciones a necesidades ya dadas.

Con respecto al nivel convencional, Kohlberg había mantenido que el niño aprendía a desempeñar aquí un rol social, entendiéndose la corrección de sus acciones en términos del «cumplimiento» o "transgresión» de normas establecidas socialmente. Desde luego que el uso ético de la razón práctica no puede reducirse sin más a la convencionalidad que representa el segundo nivel. En efecto, aunque las proposiciones éticas pretenden expresar, bajo la tesis de Habermas, que a la larga la actuación conforme a ella será buena para el sujeto o para la sociedad en que dicho sujeto habita, Habermas se cuida de no renunciar al componente crítico de los discursos ético-existenciales, es decir, a una autocomprensión hermenéutica crítica $^{32}$, donde el «arte de la comprensión de la tradición» — tal es la forma en que el propio Gadamer define la hermenéuti$\mathrm{ca}^{33}$ - , entendido como un autocercioramiento de la identidad, se convierte en reflexión encaminada a «disolver autoengaños». En este sentido de una tradición que se ha vuelto reflexiva es mucho más problemática la equiparación entre nivel convencional y uso ético de la razón. Asimismo, y tal y como muestra Conill en su Ética hermenéutica, no puede despreciarse el valor de las tradiciones éticas particulares en tanto «fuentes morales» ${ }^{34}$.

31 Habermas, J., La reconstrucción del materialismo histórico, cap. III, 74.

32 En su Ética hermenéutica, Jesús Conill ha desarrollado una ética hermenéutica con sentido crítico, capaz de eludir las acusaciones de conformismo moral-político de que puede ser objeto la hermenéutica.

33 Gadamer, H. G., La razón en la época de la ciencia, 67.

34 Conill, J., Ética hermenéutica, 258 y ss. 
$\mathrm{Al}$ margen de esto, la interpretación cultural de las necesidades con que el niño se maneja en este nivel parece guardar ciertas semejanzas con el proceso, que Habermas reserva al uso ético de la razón, de una «comprensión apropiadora» de la propia biografía y de la propia tradición. En cualquier caso, parece que en los discursos ético-existenciales el criterio no es tanto la validez universalizable de las normas cuanto la autenticidad de una forma de vida particular «en que [los implicados] se encuentran estando fácticamente», lo cual no puede dejar de hacer alguna referencia al estadio cuarto.

Como sabemos, sólo en los discursos moral-prácticos los sujetos «exigen la ruptura con todas las obviedades de la eticidad concreta asimilada por acostumbramiento ${ }^{35}$. Esta ruptura, y esto sí parece claro, se corresponde exactamente con el tránsito al nivel posconvencional. En este nivel el niño aprende a cuestionar la validez de los roles y las normas de acción socialmente establecidas de acuerdo con principios de conciencia que él mismo considera universales. El juicio moral, por así decirlo, no apela ya a la validez de un mundo social de la vida particular. Sólo ahora el hasta el momento «espontáneo proceso de interpretación de las necesidades», dependiente todavía de la transmisión cultural e institucional, puede él mismo convertirse en «objeto de formación discursiva de la voluntad ${ }^{36}$. En este último nivel surge la crítica y la justificación de las necesidades interpretadas como guías autónomas de la acción.

Como se observa, la ética discursiva y la teoría del desarrollo moral comparten un concepto constructivista de aprendizaje; mientras que Kohlberg habla de acercamiento progresivo a la estructura del juicio imparcial, Habermas ve la formación de la voluntad discursiva como «la forma reflexiva de la acción comunicativa [que] exige un cambio de actitud para la transición de la acción al discurso, cambio de actitud que el niño que crece dentro de la praxis cotidiana comunicativa no puede dominar desde el comienzo» ${ }^{37}$.

Por otra parte, y como es evidente, ninguna biografía se agota en uno y sólo uno de estos usos de la razón práctica. En el contexto de un determinado mundo de la vida, donde opera ininterrumpidamente un poso de certezas presupuestas, los sujetos orientan su acción recurriendo a los potenciales ofrecidos por la tradición, las normas fácticamente establecidas, las preferencias valorativas o los fines particulares que se pretenden alcanzar. Sólo en el discurso práctico acontece esa peculiar elevación reflexiva de las pretensiones de validez implícitas en toda forma comunicativa cotidiana, cuyo objetivo es la discusión crítico-argumentativa de las normas morales que hayan sido problematizadas por los propios participantes. Por su parte, aunque Kohlberg sostiene que el modelo de estadios no encaja tanto con un modelo acumulativo como con uno de «secuencia no acumulativo» - lo cual en principio difiere del modelo habermasiano, tal y como lo acabamos de definir-, demuestra empíricamente que

35 Habermas, J., Aclaraciones a la ética del discurso, cap. V, 121.

36 Habermas, J., La reconstrucción del materialismo histórico, cap. III, 74.

37 Habermas, J., Conciencia moral y acción comunicativa, cap. IV, 130. 
únicamente en torno al 50\% de los juicios morales de un niño encajan en un único y determinado estadio, de suerte que los demás están distribuidos entre los inmediatamente inferiores y los superiores:

El perfil de respuesta de un individuo representa un modelo compuesto por el estadio dominante en el que el sujeto se encuentra, un estadio que está abandonado pero que todavía utiliza y un estadio hacia el que se mueve pero que no ha «cristalizado» todavía ${ }^{38}$.

Esto parece sugerir la idea de una suerte de complementariedad o simultaneidad entre los diversos estadios, similar a la que Habermas defiende para los usos de la razón práctica.

Las consideraciones precedentes conducen a no descartar a priori la equiparación entre los tres usos de la razón práctica formulados por Habermas y los tres niveles evolutivos de la teoría de Kohlberg. Aunque resulta especialmente problemática la equiparación entre el uso ético de la razón práctica y el nivel convencional, parece razonable aceptar una correlación entre el nivel posconvencional y el uso moral. El propio Habermas acepta esta tesis cuando afirma que en el procedimiento discursivo de justificación crítica de normas, es decir, en el uso moral, «tienen lugar las operaciones que exige Kohlberg para los juicios morales en la esfera posconvencional» ${ }^{39}$, a saber, la reversibilidad de los puntos de vista de los participantes, la universalidad o inclusión de todos los afectados y la reciprocidad de un igual reconocimiento de las pretensiones de cada participante. Y es que el propio Habermas caracteriza la ética discursiva como una suerte de «reconstrucción racional» que consigue dar cuenta del kantiano «punto de vista moral», es decir, del «núcleo universal» de nuestras propias intuiciones morales, que ya se dan de hecho en el estadio sexto como el objetivo cumplido del aprendizaje moral ${ }^{40}$.

Esta conclusión justifica una equiparación entre el estadio sexto del nivel posconvencional, el uso moral de la razón práctica y, en definitiva, el concepto mismo de justicia, en tanto el nivel más avanzado de desarrollo ontogenético de la conciencia moral no es otra cosa que el punto de vista moral mismo, entendido como lugar que garantiza la imparcialidad del juicio. En efecto, la formación de este punto de vista moral, que en la teoría habermasiana acontece en el discurso racional, implica también una diferenciación entre las cuestiones estrictamente morales, es decir, las cuestiones de justicia que pueden resolverse racionalmente "atendiendo a la posibilidad de universalizar intereses», y las cuestiones evaluativas, esto es, las cuestiones relativas a la vida buena, que «sólo son accesibles a una discusión racional dentro del horizonte no problemático de una forma de vida históricamente concreta» ${ }^{41}$. Aunque Habermas

38 Kohlberg, L., Psicología del desarrollo moral, 90.

39 Habermas, J., Conciencia moral y acción comunicativa, cap. III, 127.

40 Véase Habermas, J., Aclaraciones a la ética del discurso, cap. III y IV.

${ }^{41}$ Ibidem, cap. II, 43. 
reconoce que con el advenimiento de la sociedad multicultural ${ }^{42}$ «el universo de cuestiones que se pueden responder racionalmente desde el punto de vista moral se encoge ${ }^{43}$, señala también la urgencia de dar respuesta a estas cuestiones en vistas a lograr una convivencia justa ${ }^{44}$.

La ética discursiva ofrece un procedimiento para enjuiciar de forma imparcial, esto es, desde el punto de vista moral, un conflicto moral. Este procedimiento se basa en una relectura comunicativa del imperativo categórico, de suerte que la imparcialidad del juicio «queda asegurada mediante un principio de universalización que distingue como válidas todas y solo las normas que todos podrían querer ${ }^{45}$. Expondremos ahora brevemente las tendencias naturalistas en ética, antes de analizar si dicha naturalización puede esperar éxito aplicada al concepto de justicia, tal y como acaba de ser definido.

\section{ESQUEMAS DE UNA EXPLICACiÓN NATURALISTA DE LA MORAL}

Aunque la pretensión de una naturalización de la ética, tal y como ha sido descrita en la introducción, bebe hoy tanto del evolucionismo como de la genética y la neurobiología ${ }^{46}$, nosotros vamos a limitarnos a ofrecer algunos rasgos de la tentativa evolucionista.

Dentro del marco evolutivo, consideramos que pueden localizarse dos momentos explicativos de la moralidad. El primero de ellos vendría a investigar el surgimiento filogenético de la agencia moral; el segundo trataría de aplicar algunos de los términos evolutivos empleados en dicha investigación — tales como «éxito adaptativo», «adaptación» o «reputación social»—a una explicación ontogenética de la agencia moral ya constituida. En el punto V se intentará mostrar que si bien el primer esquema resulta imprescindible para una correcta aproximación al fenómeno moral, el segundo sólo puede esperar cierto éxito si se limita a los niveles inferiores de desarrollo ontogenético, pero no si refiere al nivel genuinamente moral — tal y como ha sido descrito previamente.

42 Para un estudio del fenómeno de la interculturalidad en perspectiva neuroética véase ConILL, J., «La interculturalidad en diálogo con la neurofilosofía práctica».

43 Habermas, J., Aclaraciones a la ética del discurs, cap. VI, 208.

44 Habermas ha insistido en la necesidad de no excluir sin más de la tematización racional las cuestiones éticas. En Facticidad y Validez sostiene que una versión rígida del principio de neutralidad cosmovisiva podría alejar del discurso público precisamente aquellas cuestiones que, consideradas tradicionalmente privadas, constituyen sin embargo fuentes de opresión. Siguiendo a Nancy Fraser, Habermas pone el ejemplo de la tematización feminista de la violencia machista. Véase Habermas, J., Facticidad y validez, 190 y 191; Fraser, N., «Rethinking the Public Sphere».

45 Habermas, J., Aclaraciones a la ética del discurso, cap. III, 60.

46 Para un estudio de las relaciones entre filosofía práctica y neurociencias, véase Cortina, A. (ed.), Guía Comares de Neurofilosofía práctica. 
Con respecto al primer esquema, algunos autores, a los que Richard Joyce llama "sprandrel theorists» ${ }^{47}$, han tratado de explicar los fenómenos de la conciencia y agencia morales en términos de un "subproducto evolutivo», entendido éste como una estructura fruto de la compleja concurrencia de ciertos rasgos psicológicos más elementales, los cuales serían a su vez adaptaciones evolutivas, esto es, características constituidas a través del proceso de selección natural para desempeñar funciones específicas ${ }^{48}$. Algunos de los «ingredientes» detectados por estos autores serían la capacidad de prever las consecuencias de las acciones (Ayala), la facultad de abstracción (Prinz), la capacidad de usar imperativos no hipotéticos (Nichols) o la imaginación (Koorsgaard). Otros autores, entre los que se cuenta el propio Joyce, entienden que la agencia moral es ella misma una adaptación, es decir, un rasgo constituido específicamente por la evolución ${ }^{49}$. Al margen de esta discusión, cuya solución excede en mucho las capacidades de este trabajo, parece ya fuera de toda duda que una explicación de la filogénesis de la moral ha de contar con la teoría de la evolución, toda vez que la estructura biológica en que aquélla se basa ha sido constituida por las fuerzas de la selección natural. Las tendencias hacia la cooperación y el altruismo, por así decirlo, no son un mero «velo cultural», sino que «los humanos han sido diseñados por la selección natural para ser gregarios y cooperativos» ${ }^{50}$.

En este sentido se ha pronunciado también recientemente Michael Tomase$1 \mathrm{l}^{51}$. En su análisis filogenético de la moralidad, Tomasello argumenta que la especificidad de la cooperación humana con respecto a la de otros primates ${ }^{52}$ - y por tanto la aparición de la moralidad, tal y como él la entiende- fue el fruto de un cambio evolutivo acontecido en dos pasos. En un primer momento, en la búsqueda por evitar las carencias asociadas a la actuación solitaria - como el hambre o el peligro de muerte-, los humanos se vieron biológicamente impelidos a la colaboración. Esto es lo que sostiene el propio Darwin cuando explica la sociabilidad de los primeros humanos como fruto directo de la selección natural, en el sentido de que resultó más provechoso para la supervivencia el poseer dicha cualidad ${ }^{53}$. Estas interacciones sociales, así reza la tesis de

47 Joyce, R., «The origins of moral judgment», 126.

48 Para un estudio sistemático del origen evolutivo de la agencia moral véase en este mismo volumen de la revista Pensamiento RichaRT, A., «El origen evolutivo de la agencia moral y sus implicaciones para la ética».

49 Ayala, F. J., «Las raíces biológicas de la moral»; PRINZ, J., «Is morality innate?»; Nichols, S., "Innates and moral cognition»; KoorsgaARD, C., Las fuentes de la normatividad; Joyce, R., The evolution of morality.

50 Joyce, R., «The origins of moral judgment», 130.

51 Tomasello, M. y Vaish, A., "Origins of Human Cooperation and Morality».

52 Para una discusión sobre las especificidades del ser humano a este respecto en relación con otros primates, véase de WAAL, F., "The chimpanzee's sense of social regularity and its relation to the human sense of justice». El sentido de la justicia que De Waal atribuye a los chimpancés no coincide sin más con la noción que nosotros tratamos de apresar bajo la idea de «nivel posconvencional» o «uso moral de la razón práctica».

53 DaRwin, Ch., El origen del hombre. La selección natural y la sexual, 135 y ss. 
Tomasello, dieron ocasión a que los individuos fueran desarrollando progresivamente nuevas habilidades y «formas de compromiso social» con segundas personas. La creciente interdependencia de los distintos sujetos entre sí propició que cada individuo se sintiera directamente interesado por el bienestar del resto de individuos de su entorno. Justamente aquí acontece la aparición filogenética del fenómeno de la reputación, que se explica evolutivamente por la necesidad surgida en los individuos de ser percibidos como sujetos colaborativos, en tanto tal percepción habría de garantizarles futuros beneficios. Darwin ve en este motivo, y no en la mera reciprocidad, el estímulo más poderoso para la reproducción de los sujetos altruistas. El actuar conforme al «amor al elogio o miedo a la infamia» favoreció la supervivencia del propio grupo frente a otros, realizándose así la selección natural.

Según la tesis de Tomasello, sólo en un segundo momento el incremento de la rivalidad entre diversos grupos hizo emerger una conciencia grupal, específicamente humana, que extrapoló la antes individual motivación colaborativa a la vida del grupo en su conjunto. Bajo el interés evolutivo de preservar la supervivencia del grupo, la acción social humana fue transitando hacia una forma abstracta y normativa de cooperación, que a juicio de Tomasello marca la moralidad ya constituida del ser humano moderno.

La tesis central de Tomasello en el trabajo citado, según la cual estos dos pasos evolutivos acontecen de forma paralela en el contexto ontogenético, da ocasión a analizar el segundo esquema a que nos referimos más arriba. Este esquema abandona el campo de estudio filogenético y trata de exportar los conceptos de la teoría de la evolución a una explicación ontogenética de la conciencia moral. Ya a una edad muy temprana, sostiene Tomasello, los niños aprenden a anticipar que serán juzgados por su comportamiento, lo que les incita a actuar de manera tal que «incrementen las evaluaciones positivas y decrezcan las negativas» ${ }^{54}$ que los demás sujetos tienen sobre ellos; es decir, a actuar colaborativa y prosocialmente. En un estadio más tardío los sujetos comienzan a considerar a los demás como miembros de un grupo más amplio al que ellos mismos pertenecen, aprendiendo a valorar por sí mismas — y no ya por temor al castigo o por los imperativos específicos del adulto- las normas que el grupo se ha dado a sí mismo. Con este tránsito el niño se convierte, por así decirlo, en un sujeto plenamente socializado; y en este sentido también en un sujeto moral.

Como se observa, aunque la teoría de la selección de grupos no puede responder al fenómeno del altruismo individual con sujetos ajenos al propio grupo - entendiendo el altruismo, tal y como lo define Simon, no como un mero intercambio de favores recíprocos, sino como «un comportamiento que incrementa, por regla general, la salud reproductiva de otros a costa de la salud del propio altruista» ${ }^{5}$ - el estímulo, explicado por Darwin, de la búsqueda de re-

54 Tomasello, M. y VAish, A., «Origins of Human Cooperation and Morality».

55 Simon, H. A., "A Mechanism for Social Selection and Successful Altruism». 
putación social sí parece ofrecer una respuesta satisfactoria a dicho fenómeno. En la medida en que los comportamientos altruistas son apreciados por la colectividad, tal es la tesis, y que los comportamientos egoístas son despreciados, los primeros suponen un incremento de la reputación social del sujeto que los realiza, mientras que los segundos suponen un incremento de la vergüenza social. Evidentemente, dentro de un grupo son los sujetos reputados los que tienen mayores posibilidades de reproducirse, y en este sentido el altruismo individual parece poder explicarse también en los términos del éxito adaptativo. Sería, por así decir, una suerte de interiorización de normas de conducta basadas en la lógica de la reciprocidad indirecta ${ }^{56}$.

Aplicado al fenómeno específico de la conciencia moral, Adela Cortina ${ }^{57}$ ha destacado dos explicaciones diferentes desde la teoría de la evolución: o bien se entiende ésta como «una voz estratégica que nos aconseja cómo alcanzar nuestros intereses de forma prudente, sin soliviantar al grupo que puede castigarnos ${ }^{58}$; o bien como una identificación con los valores y reglas del grupo de pertenencia, identificación que haría surgir el sentimiento de vergüenza ante la transgresión normativa.

Creo que Cortina acierta al formular la siguiente objeción al paradigma naturalista-evolutivo: "¿y si el infractor no fuera descubierto, con lo cual no habría lugar para la pérdida de reputación ni tampoco para la vergüenza?» ${ }^{59}$. El fenómeno del comportamiento moral independientemente de su valor estratégico parece apuntar hacia una cuestión particularmente interesante, que escapa al marco conceptual de la teoría evolucionista ${ }^{60}$. Tal vez la figura del disidente político, cuya disidencia se fundamenta en una contradicción entre su concepción de la justicia y las normas socialmente establecidas, ejemplifique mejor que ninguna otra esa sustracción del comportamiento moral a la mera identificación con las normas, adaptativamente provechosas, que rigen dentro de un grupo social ${ }^{61}$. A analizar esta trascendencia de lo sólo convencionalmente

56 Véase Izuma, K., «The social neuroscience of reputation».

57 Cortina, A., «La conciencia moral: entre la naturaleza y la autonomía».

58 Cortina sitúa dentro de esta explicación la propuesta de R. Alexander. Véase AlexANDER, R., The biology of moral systems.

59 CoRtina, A., «La conciencia moral: entre la naturaleza y la autonomía».

60 Desde el punto de vista de la teoría del reconocimiento, Cortina emite una crítica al contractualismo heredero del modelo evolucionista. Ante la decisiva pregunta de a quién deben proteger las leyes de una comunidad política, tal es la argumentación, la respuesta coherente con el marco evolutivo sería la siguiente: a los que son capaces de actuar de forma recíproca dentro de su grupo social. Evidentemente, esta respuesta resulta contradictoria con la posconvencional idea de justicia moderna, según la cual la comunidad política ha de proteger por igual a todos sus ciudadanos. Véase CorTinA, A., Neuroética y neuropolítica.

${ }_{61}$ Por supuesto, la disidencia política no garantiza sin más la referencia a una concepción posconvencional de la justicia: también el golpista, que trata de universalizar sus intereses particulares, es un disidente. Por otra parte, las normas socialmente establecidas pueden encarnar también una concepción posconvencional de la justicia, como de hecho pretende, con más o menos éxito, el moderno Estado Social de Derecho. 
considerado como justo dedicaremos el último punto, y en concreto a estudiar la imposibilidad de explicarla en términos de éxito evolutivo ${ }^{62}$.

\section{6. ¿Naturalizar La idea de Justicia?}

Si el uso moral de la razón práctica ha de poder ser identificado con el estadio último del desarrollo ontogenético de la conciencia moral — como se ha tratado de probar-, y si a su vez esta culminación ontogenética puede corresponderse con la idea de justicia, tal y como la han entendido las modernas teorías de raíz kantiana, entonces es preciso aclarar en qué sentido el naturalismo ético afecta también al propio concepto de justicia.

La pretensión de una naturalización de la ética no puede querer limitarse, si es que ha de ser coherente consigo misma, precisamente al tipo de normas de acción que más problemáticamente cabe categorizar como normas morales. Y con todo es precisamente esto lo que hace. La regulación de la conducta de los miembros de un determinado grupo social con objeto de obtener ciertas ventajas funcionales no puede sin más recibir el nombre de «normas morales» ${ }^{63}$. También el derecho positivo, el conjunto de normas sociales asentadas en una sociedad por acostumbramiento o las claramente convencionales normas de convivencia - como las señales de tráfico o los protocolos de comportamiento-, representan modos de regular la conducta de acuerdo con intereses grupales. Partir de una comprensión de la moralidad como un «conjunto de valores y usos comunes abrazados por un grupo cultural para guiar su conducta social $\aleph^{64}$, comprensión que descarta por definición la existencia de normas morales universales, allana el camino del éxito a la explicación naturalista. Pero lo hace al precio de desvirtuar la especificidad del fenómeno moral. La moral no es un «lubricante» que mejore el funcionamiento de la sociedad, sino una condición sine qua non para la propia vida social, un «dispositivo protector» encaminado a compensar la vulnerabilidad «por así decir constitucional», la «crónica fragilidad» de que es objeto la identidad personal en su socialización ${ }^{65}$.

Si la conciencia moral, al margen de las cuestiones que tienen que ver con la presión de grupo o la búsqueda de beneficios recíprocos, «tiene también un componente de obligación interna» ${ }^{66}$, como dice Cortina siguiendo a Kant; si

62 Jesús Conill ofrece una sugerente lectura del concepto de «intimidad corporal» como "poder para orientar la acción» más allá de la mencionada búsqueda de reputación social. Véase ConILL, J., «La intimidad corporal y sus bases neurobiológicas», en este mismo monográfico.

63 Domingo García Marzá ha insistido en la necesidad de diferenciar «normas sociales» y «normas morales». Véase GARCíA MARŹ́, D., Ética de la justicia; «Neuroética aplicada y recursos morales: la aportación de las neurociencias».

64 Moll, J. «The neural basis of human cognition».

65 Habermas, J., Aclaraciones a la ética del discurso, cap. I, 18. 19.

66 CoRtinA, A., «La conciencia moral: entre la naturaleza y la autonomía». 
existe en las normas genuinamente morales una suerte de fuerza obligatoria incondicionada, que no remite ya a las ventajas adaptativas del sujeto que se orienta conforme a ellas, sino más bien a una posible fundamentación racional - que la ética del discurso busca en la posible aceptabilidad de todos los afectados en tanto normas justas; principio al cual subyace, como es sabido, la kantiana consideración de la persona como fin en sí mismo-, entonces el modelo explicativo naturalista de la conciencia moral como "voz estratégica» que recomienda las técnicas más adecuadas para conseguir fines presupuestos, tales como la aceptación en el seno de un determinado grupo, ya no puede referir más que a los niveles pre y convencional; o dicho de otra forma, ya no puede ser aplicado sin más a lo que, según se ha defendido, constituye el uso genuinamente moral de la razón. Y esto por mucho que un estudio de la conciencia y agencia morales no pueda prescindir en ningún caso de una explicación filogenética de la moral en términos de teoría de la evolución.

Evidentemente, tiene sentido aplicar el vocabulario evolucionista del éxito adaptativo a los niveles inferiores de desarrollo ontogenético. El evolucionismo explica bien las cuestiones relativas a una organización pacífica de la sociedad, y para ello recurre al instrumento de un conjunto de normas que el sujeto interioriza a fin de evitarse el reproche social. En los estadios correspondientes al nivel preconvencional, la actuación instrumentalista del niño con respecto al resto de miembros de su grupo, actuación ciertamente encaminada a una satisfacción de las propias necesidades, encaja bastante bien con el modelo de la reciprocidad directa que utiliza la teoría de la evolución; este modelo se acopla igualmente, como hemos tratado de mostrar en el punto tercero, a lo que Habermas llama «uso pragmático de la razón práctica». Por su parte, en los estadios tres y cuatro, correspondientes al nivel convencional, el objetivo del niño - agradar a los miembros del grupo y preservar el orden y la autoridad establecidos por mor de sí mismos- encuentra una clara correlación con el concepto evolucionista de «reputación». En efecto, el comportamiento moral se explica aquí recurriendo a la pretensión, por parte del sujeto, de evitar la reprobación social y preservar un status positivo dentro del grupo en vistas a futuras recompensas — por muy indirectas que éstas puedan ser.

Al margen de la problemática hipótesis de equiparar este nivel convencional con el uso ético de la razón, cabría preguntarse qué sucede con el último nivel de desarrollo ontogenético. El nivel posconvencional, donde surge al fin la conciencia moral, exige una forma de auto-obligación incondicionada que ya no puede explicarse recurriendo al éxito adaptativo. Por eso dice Cortina que «existe un mundo moral específico que ordena incondicionadamente asumir reglas cuando se consideran justas y recusarlas cuando se consideran injustas, sean o no las del grupo ${ }^{67}$. Este "sean o no las del grupo" apresa la posconvencionalidad característica de la norma moral. Y esto es lo que Habermas llama «uso moral de la razón», Kohlberg «nivel posconvencional de desarrollo del jui-

67 Ibidem. 
cio moral», y nosotros, siguiendo la lógica habermasiana, punto de vista moral o ámbito de la justicia.

La interpretación cognitivista de la validez deontológica, tal y como la defienden Habermas y Kohlberg, colisiona precisamente con aquella concepción naturalista según la cual los mandatos morales «reflejan únicamente sentimientos de obligación que se pueden remitir a la interiorización de las sanciones con las que se nos ha amenazado» (nivel preconvencional), o con la «concepción no cognitivista de que el interés recíproco en el cumplimiento de las normas se puede remitir en último término al interés por la propia estima» 68 (nivel convencional). La sanción, lo que el sujeto interioriza como sanción, es en verdad «el miedo a la excomunión de una comunidad con la que está identificado» ${ }^{69}$. Evidentemente, esta lógica es en rigor la propia del nivel convencional.

Frente a esto, una moral no convencional ha de hacer alusión a un punto de vista imparcial para el enjuiciamiento de normas, es decir, a un punto de vista moral, que en ningún caso puede quedar reducido a la interiorización de sanciones sociales para la reproducción de un sistema normativo ya existente ${ }^{70}$.

De igual forma que en la teoría de Kohlberg las transiciones de un nivel a otro presuponen un modelo constructivista de aprendizaje, entendido dicho aprendizaje como un «acercamiento paulatino a las estructuras del juicio imparcial o justo de los conflictos de acción moralmente relevantes» ${ }^{71}$, en la ética discursiva se entiende la adopción del punto de vista moral como un tránsito desde la acción al discurso. Naturalmente, la conciencia moral sólo atañe a las cuestiones especificamente morales. No en vano Habermas define la conciencia moral como «la capacidad de servirse de la competencia interactiva para una elaboración consciente de conflictos de acción relevantes en perspectiva moral» ${ }^{72}$. Para solucionar consensualmente un conflicto se requiere un punto de vista generador de consenso, y este punto de vista deriva a juicio de Habermas de las propias «estructuras de la interacción». El discurso ofrece al sujeto un lugar crítico, imparcial, desde el que someter a prueba las pretensiones de validez que, dándose ya implícitamente en toda praxis comunicativa cotidiana, han sido problematizadas por los participantes. Resulta extraordinariamente significativo que Habermas describa este tránsito al discurso como algo antinatural, en tanto implica «una ruptura con la ingenuidad de las aspiraciones de validez formuladas $»^{73}$. Con el paso al nivel posconvencional se introduce una «actitud hipotética» con respecto a las certidumbres previamente indiscutidas del mundo de la vida. La reflexión crítica despoja a este mundo de la vida «de

68 Habermas, J., Aclaraciones a la ética del discurso, cap.VI, 150.

69 Ibidem, 156.

70 Habermas llama a esto "comprensión empirista de la validez normativa». Verdad y justificación, 267.

71 Habermas, J., Conciencia moral y acción comunicativa, cap. IV, 128.

72 Habermas, J., La reconstrucción del materialismo histórico, 77.

73 Habermas, J., Conciencia moral y acción comunicativa, cap. IV, 128 y 131. 
su índole originariamente natural» ${ }^{74}$, y la conformidad con los roles y normas sociales tradicionales queda remitida a las exigencias de justicia. La moral, tal y como se expresa Habermas en Facticidad y validez, "suministra los puntos de vista para proceder a un enjuiciamiento «desencantador» de las instituciones existentes ${ }^{75}$.

Habermas sabe que con esta actitud hipotética se pierde el «anclaje motivacional» de la convicción moral. El discurso racional es un instrumento para la justificación crítica de normas, pero ha de permanecer mudo ante la cuestión de por qué debería el sujeto que en él participa comportarse conforme a las normas así fundamentadas. Esta pérdida motivacional ha de ser suplida tanto por el derecho, ante cuya coacción uno ya no tiene por qué preguntarse por los motivos para el cumplimiento de la norma, como por un modo de tradición que, siendo también fuente moral, adopte un carácter reflexivo; esto es, "que haga depender la renovación de la tradición de la disposición a la crítica ${ }^{76}, \mathrm{y}$ por tanto que impulse el cumplimiento de la norma moral cortada a la medida posconvencional $^{77}$.

Desde luego que de una concepción preconvencional de la corrección normativa, donde la adhesión a las normas depende o bien del concepto de obediencia o bien del de reciprocidad de compensaciones; así como de una concepción convencional, que se basa fundamentalmente en el respeto a una autoridad que garantiza ciertas expectativas de comportamiento en el seno de un determinado mundo social de la vida, da buena cuenta la explicación naturalista. Frente a estos dos momentos, sin duda necesarios en el proceso socializador, Habermas entiende que «la idea de justicia sólo puede extraerse de la forma ideal de una reciprocidad realizada en el discurso ${ }^{78}$. El universalismo moral que subyace a esta explicación, tal es la tesis que ha tratado de probarse en este trabajo, sencillamente no puede ser abordado desde los términos que ofrecen hoy las corrientes naturalistas.

\section{CONCLUSIONES}

El presente artículo ha tratado de mostrar en qué sentido las evidencias aportadas por la teoría de la evolución, las cuales resultan ciertamente necesarias para estudiar la filogénesis de la conciencia y agencia morales, no pueden cancelar el curso de la investigación en teoría moral, al contrario de lo que pretende la tradición positivista. Nuestra tesis ha sido que los estadios

74 Habermas, J., Aclaraciones a la ética del discurso, cap. III, 81.

75 Habermas, J., Conciencia moral y acción comunicativa, cap. IV, 128 y 131.

76 Habermas, J., Aclaraciones a la ética del discurso, cap. II, 49.

77 Con su ética de la razón cordial, que prioriza el reconocimiento de los sujetos mediante la categoría de «respeto», Cortina trata de completar el hueco abierto entre fundamentación y aplicación de la norma moral.

78 Habermas, J., Conciencia moral y acción comunicativa, cap. IV, 173. 
ontogenéticos más avanzados de la conciencia moral no pueden ser explicados de acuerdo con un marco evolutivo que, en el ámbito ontogenético, aborda la moralidad en términos de búsqueda de reputación social, por mucho que los niveles previos sí parezcan susceptibles de dicha explicación.

Por otra parte, si la teoría moral de Habermas es capaz de ofrecer un fundamento normativo para el cuestionamiento crítico de normas - a saber, el consenso intersubjetivo de todos los afectados en un diálogo celebrado en condiciones de simetría-, una ética naturalizada tiene que limitarse a juzgar las normas de acción de acuerdo con el nada crítico principio biológico del éxito evolutivo. «Bajo la inflexible mirada moralizante del participante en el discurso», dice Habermas - y con esto quiere significar «bajo el punto de vista de una moral posconvencional»—, la eticidad del mundo de la vida «ha perdido su validez natural, y la fuerza normativa de lo fáctico su vigor» ${ }^{79}$. A la luz de esta tesis, según la cual toda tradición o norma social cuenta como hipótesis «en tanto no recupere su validez mediante la autoridad de buenas razones», quisiera terminar ensayando, a modo de conjetura para un futuro trabajo, una posible conexión entre el naturalismo y las posturas ético-políticas convencionalistas, que son por definición conservadoras ${ }^{80}$.

Sospecho que la conclusión a que llega Habermas en su disputa contra los posicionamientos neoaristotélicos, según los cuales el juicio moral no puede desvincularse del ethos dominante en cada comunidad concreta, puede también aplicarse a la discusión con el naturalismo, en tanto este último recurre igualmente a una categorización pre-kantiana de moralidad —esto es, a una noción ni posconvencional ni universalista. Describiendo el gesto hegeliano, Habermas se expresa como sigue:

Hegel propuso que la comprensión moderna del mundo ya no puede retroceder a un estadio anterior a la noción kantiana de moralidad, comoquiera que se reformule esta última, a no ser pagando por ello el precio de regresiones políticas ${ }^{81}$.

De dar por válida nuestra hipótesis, las actuales tendencias naturalistas en ética dejarían de lado precisamente la especificidad de una moral entendida posconvencionalmente, y en este sentido supondrían un retroceso con respecto a la noción kantiana de moralidad. Una ética naturalizada sólo puede comprarse al precio de una renuncia al contenido eminentemente crítico que acompaña a todo universalismo moral. La renuncia a dicho contenido, en fin, deja vacío el impulso emancipador a que conduce la distinción entre normas fácticamente reconocidas y normas merecedoras de reconocimiento.

79 Habermas, J., Aclaraciones a la ética del discurso, cap. II, 42.

80 Exactamente lo contrario defiende James Rachels en su artículo «When philosophers shoot from the hip». Los defensores de una ética deontológica y universalista caerían del lado conservador, en tanto se limitarían a responder intuitivamente —en función de lo convencionalmente establecido- a las inquietudes morales.

${ }^{81}$ Habermas, J., Aclaraciones a la ética del discurso, cap. II, 46. 


\section{BibliografíA}

Alexander, R., The biology of moral systems, Aldine de Gruyter, Hawthorne, NY, 1987. Apel, K. O., Hermeneutik und Ideologiekritik, Suhrkamp, Frankfurt, 1971.

Ayala, F. J., La evolución de un evolucionista, Universidad de Valencia, Valencia, 2006. Conill, J., «El carácter hermenéutico y deliberativo de las éticas aplicadas», en: Cortina, A. y García-Marzá, D. (eds), Razón pública y éticas aplicadas, Tecnos, Madrid, 2003, 121-142.

Conill, J., Ética hermenéutica, Tecnos, Madrid, 2006.

Conill, J., «La interculturalidad en diálogo con la neurofilosofía práctica», en: Thémata, $52,2015,77-92$.

Conill, J., «La intimidad corporal y sus bases neurobiológicas», en: Pensamiento.

Cortina, A., Ética mínima, Tecnos, Madrid, 1994.

Cortina, A., Ética de la razón cordial, Nobel, Oviedo, 2007.

Cortina, A., Justicia cordial, Trotta, Madrid, 2010.

Cortina, A., Neuroética y neuropolítica, Tecnos, Madrid, 2011.

Cortina, A. (ed.), Guía Comares de Neurofilosofía práctica, Comares, Granada, 2012.

CortinA, A., "La conciencia moral: entre la naturaleza y la autonomía», en: Cuadernos Salmantinos de filosofía, 40, 2013, 249-262.

Cortina, A., «La conciencia moral desde una perspectiva neuroética. De Darwin a Kant», en: Pensamiento.

DARwin, Ch., El origen del hombre. La selección natural y la sexual, Prometeo, Valencia, s. f.

DE WAAL, F., «The chimpanzee's sense of social regularity and its relation to the human sense of justice», en: Masters, R. y Gruter, M. (eds.), The sense of justice: biological foundations of law, Sage Publications, Newbury Park, CA, 1992, 241-255.

Fraser, N., «Rethinking the Public Sphere», en: Calhoun, C. (ed.), Habermas and the Public Sphere, Mass., Cambridge, 1992.

GadAmer, H. G., La razón en la época de la ciencia, Alfa, Barcelona, 1981.

García Marzá, D., Ética de la justicia, Tecnos, Madrid, 1992.

García MARZÁ, D., «Neuropolítica y democracia: un diálogo necesario», en: Daimon, 59, 2013, 171-182.

GARCía MARZÁ, D., «Neuroética aplicada y recursos morales: la aportación de las neurociencias». Simposio Internacional Naturaleza Humana 2.0, Madrid, Universidad de Comillas, 2016.

Habermas, J., Problemas de legitimación en el capitalismo tardío, Amorrortu, Buenos Aires, 1973.

Habermas, J., La reconstrucción del materialismo histórico, Taurus, Madrid, 1992.

Habermas, J., Aclaraciones a la ética del discurso, Trotta, Madrid, 2000.

Habermas, J., La lógica de las ciencias sociales, Tecnos, Madrid, 2000.

Habermas, J., Entre naturalismo y religión, Paidós, Barcelona, 2006.

Habermas, J., Conciencia moral y acción comunicativa, Trotta, Madrid, 2008.

Habermas, J., Facticidad y validez, Trotta, Madrid, 2010.

Habermas, J., Verdad y justificación, Trotta, Madrid, 2011.

Izuma, K., «The social neuroscience of reputation», en: Neuroscience Research, 72, 2012, 283-288.

Joyce, R., The evolution of morality, Mit Press, Cambridge, MA, 2006. 
Joyce, R., «The origins of moral judgment», en: De Waal, F. B., Churchland, P. S., PievaNI, T. y Parmigiani, S. (ed.), Evolved Morality. The Biology and Philosophy of Human Conscience, BRIL, Boston, 2014.

Kitcher, P., «Is a naturalized ethics possible?», en: De WaAl, F. B., Churchland, P. S., Pievani, T. y Parmigiani, S. (ed.), Evolved Morality. The Biology and Philosophy of Human Conscience, BRIL, Boston, 2014, 109-124.

Kohlberg, L., «From Is to Ought», en: Mishel, T. H. (ed.), Cognitive Development and Epistemology, New York, 1971, 151-236.

Kohlberg, L., Psicología del desarrollo moral, Desclée de Brouwer, Bilbao, 1992.

KoorsgaArd, C., Las fuentes de la normatividad, UNAM, México, 2000.

Moll, J., "The neural basis of human cognition», en: Nature Reviews. Neurosciencie, 6(10), 2005, 799-809.

Nichols, S., "Innates and moral cognition», en: Carruthers, P., Laurence, S. y Stich, S. (eds.), The innate mind: structure and contents, Oxford University Press, New York, 2005, 353-430.

Prinz, J., "Is morality innate?», en: SinnotT-Armstrong, W. (ed.), Moral psychology, vol. 1: the evolution of morality: adaptations and innateness, MIT Press, Cambridge, MA, 2008, 367-406.

Rachels, J., «When philosophers shoot from the hip», en: Bioethics, 5(1), 1991, 67-71.

Richart, A., «El origen evolutivo de la agencia moral y sus implicaciones para la ética», en: Pensamiento.

Ricoeur, P., Del texto a la acción, FCE, México D. F., 2002.

Ricoeur, P., «Ética y moral», en: Gómez, C. (ed.), Doce textos fundamentales de la ética del siglo XX, Alianza, Madrid, 2002.

Simon, H. A., «A Mechanism for Social Selection and Successful Altruism», en: Science, 250, 1990, 1665-1668

Tomasello, M. y VAish, A., "Origins of Human Cooperation and Morality», en: Annual Review of Psychology, 64, 2013, 231-255.

Universidad de Valencia

César Ortega Esquembre

cesar.ortega@uv.es

[Artículo aprobado para publicación en octubre de 2016] 